\title{
A formação da cultura de resistência e a experiência de luta na produção de saberes
}

\author{
Marilia de Almeida Silva* \\ Edson Caetano**
}

\begin{abstract}
Resumo
$\mathrm{Na}$ tentativa de compreender a produção ampliada da vida do povo Chiquitano que vive no Estado de Mato Grosso, identificamos a formulação de uma cultura de resistência, subjacente às experiências com os conflitos travados pelo direito de ser e de existir deste povo nos diversos contextos históricos, intensificados na sua luta atual pelo território tradicional e pela garantia plena dos direitos humanos e da natureza. $\mathrm{O}$ objetivo central deste trabalho é analisar, através das lentes do materialismo histórico-dialético, o processo educativo que se manifesta na produção material e imaterial destas mulheres e homens, a fim de refletir sobre os saberes da experiência e a educação que se faz no chão da resistência.

Palavras-chave: cultura de resistência; saberes da experiência; chiquitano.
\end{abstract}

\section{The formation of the culture of resistance and conflict experience in the production of knowledge}

\begin{abstract}
In seeking to understand the lives of the Chiquitanos people living in Mato Grosso State, extensive research has identified the formulation of a culture of resistance, underlying experiences with conflicts by the right to be and to exist of this people in different historical contexts, intensified in its current battle for traditional territory and the full guarantee of human rights and nature. The central objective of this work is to analyse, through the lens of historical and dialectical materialism, the educational process that is manifest in the material and immaterial production of these women and men, for to reflect on the experience knowledge and the education that makes in the ground of resistance.

Key words: culture of resistance; knowledge of experience; chiquitano.
\end{abstract}

\section{Introdução}

O presente artigo vem ao encontro da necessidade de analisarmos algumas categorias históricas por outro viés, não a partir das manifestações teóricas dos grupos dominantes, mas da concreticidade da vida dos 'excluídos', dando visibilidade a esta produção pela leitura de suas expressões e formas de resistência. A cultura, então, ganha contornos privilegiados enquanto um campo de disputas, conflitos e de aspiração dos desejos, ideais, necessidades e protestos, protagonizando a coesão de consciências e a elaboração de saberes. Desta forma, a produção ampliada da vida ${ }^{1}$ ocorre de diferentes formas, nos mais variados contextos histórico-culturais em que estão inseridas as sociedades humanas, e consideramos, assim, que suas respectivas culturas se configuram como o principal elemento de constituição de suas identidades e de unidade social.

Nessa perspectiva, buscamos reconhecer o germe de outra sociedade possível, contraria à hegemônica imposta, com base em princípios solidários, humanistas, preservacionistas, justos e libertários, cujo caminho nos apresentou uma infinidade de situações possíveis no estado do Mato Grosso, uma das regiões brasileiras de maior biodiversidade, plurietnicidades e

* Endereço eletrônico: lia_cultura@ hotmail.com

** Endereço eletrônico: caetanoedson@ @otmail.com multiculturalidades, para uma pesquisa da produção associada $^{2}$. Todavia, a que nos alcançou foi a história de luta e resistência que marca a vida do povo Chiquitano ${ }^{3}$, destacada pela urgência e relevância das questões de territorialidade, identidade e direitos humanos. Seu forte embate fora herdado do período colonial, agravado pelos conflitos fronteiriços e pela negação étnica que enfrentam diante do grande potencial de exploração de seus territórios e força de trabalho à qual estão submetidos.

Entramos em uma história de grandes tensões, a realidade de muitas pessoas que sofrem com as punições impostas pelos detentores do poder, com os crimes de terror cometidos pelo Estado e com a perpétua colonização em busca insaciável da exploração máxima dos recursos para a propagação de capital. Para que compreendêssemos a produção da vida chiquitano através de sua expressão étnico-cultural, marcada pelas experiências de comunhão, religiosidade e resistência, embarcamos em uma missão desafiadora, de participar do processo de luta pelos direitos dessa etnia e, ao mesmo tempo, analisar criticamente a sua construção histórica na árdua jornada antagônica aos interesses hegemônicos da sociedade capitalista.

A pesquisa moldou-se metodologicamente 
pelo caminho percorrido, caracterizando-se enquanto uma pesquisa participativa, que se apropria de ferramentas da etnografia e da historiografia para uma discussão no campo do materialismo histórico-dialético, refinado pela perspectiva renovadora do intelectual Thompson, que nota, através da análise da cultura popular, o possível germe da concreta sociedade revolucionária que vislumbramos. Nesse sentido, organizamos este artigo em três partes: na primeira discutiremos a Cultura enquanto categoria da totalidade histórica do povo chiquitano, presente no Estado brasileiro, e suas manifestações na (re)produção ampliada da vida desses indígenas; $\mathrm{Na}$ segunda parte contextualizaremos o atual conflito que vivem os chiquitanos diante das questões urgentes sobre território, identidade e direitos humanos; e, por fim, na terceira parte identificaremos alguns dos importantes saberes resultantes das experiências de luta que reconfiguram o processo educativo nas aldeias chiquitanas.

\section{Cultura, Cosmologia e a Produção Ampliada da Vida}

Discutir a cultura é dialogar sobre formas de ver o mundo. As realidades são organizadas nas consciências dos sujeitos históricos e processadas de maneira a repercutir em seus comportamentos, que na instância social tomam uma dimensão cosmológica da complexa relação de produção, material e imaterial, dos costumes, crenças, leis, artes, moral e saberes.

Os homens são os produtores das suas representações, ideias, etc. - mas se trata de homens reais e ativos, condicionados por um determinado desenvolvimento das suas forças produtivas e do intercâmbio a ele corresponde, inclusive suas formações mais desenvolvidas. [...] A moral, a religião, a metafísica e qualquer outra forma de ideologia e as formas de consciência que a $e$ elas correspondem perdem, assim, a aparência de serem independentes. Não têm história nem desenvolvimento próprios: os homens, que desenvolvem a sua produção e $o$ seu intercâmbio materiais, modificam também, ao modificar a realidade, o seu pensamento e os produtos do seu pensamento. (MARX; ENGELS, 2007, p. 93-94)

Os Chiquitanos, enquanto sujeitos históricos, desenvolveram os sentidos de sua identidade indígena e a 'do outro' a partir dos diversos conflitos desde o período colonial, quando sofrem com os primeiros genocídios em meados do século XVI, até os dias atuais, com a ameaça da extinção pela banalizada ação corrosiva do agronegócio. Ao analisar a cultura chiquitana, simultaneamente, propomo-nos a analisar suas tradições e a nova perspectiva que a redimensiona mediante os conflitos que estes indígenas foram e são submetidos.

A tradição que marca a cultura chiquitana está relacionada com a ampla práxis, baseada em uma racionalidade que pode ser considerada ancestral por ter sido passada de gerações a gerações, contudo também passível de ressignificação, de compreensão do mundo e do ser humano; ela assume um caráter dinâmico, um produto humano, resultante do acúmulo de saberes das experiências vivenciadas ao longo da história dessas mulheres e homens: "Sabemos ainda, que o 'novo' e o 'velho' vivem em complementariedade, sofrendo vários arranjos e adaptações para manterem-se enquanto tais" (SOUZA; BRANDÃO, 2009, p. 116).

Buscando compreender como se dão as atuais práticas socioculturais, foi preciso observar o processo de constituição das principais características da tradição chiquitana, que, neste caso, partem do período compreendido entre os séculos XVI e XVIII, quando o agrupamento de diferentes etnias pelos colonizadores resultou na formação étnica do povo chiquitano, cujo nome faz referência aos Chiquitos, uma das etnias mais expressivas das reduções. Um dos primeiros registros históricos na literatura, por volta de 1557 , está na descrição de Ñuflo de Chavez sobre "um [un?] terrible combate con más de viente mil indios tupuimiries o chiquitos, posuedores del secreto de la yerba" (GANDIA apud COSTA, 2006, p.46). Eles ganharam fama de guerreiros e eram temidos pela habilidade conferida pela utilização de flechas que continham veneno e por sua coragem. Como destaca Costa (2006, p. 46), "a resistência dos Chiquitos nesse início de colonização [era] efetivada muitas vezes de forma isolada e, em outras ocasiões, articuladas em amplas alianças político-militares entre os vários grupos e mesmo com inimigos tradicionais (...)". Tempos mais tarde, os autóctones Chiquitos viram-se obrigados a estreitar uma possível aliança com a Coroa Espanhola devido ao encurralamento genocida, momento propício para os Jesuítas, que já tinham a permissão para a missão de Chiquitos e Mojos. Indígenas de mais de quarenta etnias foram, então, reduzidos pelos Jesuítas na Gran Chiquitania, durante a transição do século XVII para o XVIII: 
As missões, além de conterem em um espaço restrito uma profusão de línguas distintas, não sendo incomum os índios dominarem dois ou mais idiomas, acomodavam também diferentes crenças, tantas influências quantas eram as etnias ali reduzidas. As concepções do sagrado aproximavam mais as religiões indígenas entre si do que estas com a teologia cristã, cujos mitos operavam elementos estranhos à realidade local. A convivência próxima, similaridade das cosmovisões, em que o xamanismo representa uma categoria social de mediação entre o mundo humano e o mundo dos espíritos, foi também sendo adaptada e modificada através do tempo, tomando parte de um padrão de representação de uma cultura amalgamada: a Chiquitano. (COSTA, 2006, p. 71-72)

A circularidade cultural fica evidente, não obstante o fato de que, embora reduzidos pelas missões da Igreja Católica através dos Jesuítas, os autóctones, então passando a ser chamados de Chiquitanos, não receberam passivamente o domínio cultural, tampouco conceberam como suas as concepções inerentes às novas práticas de produção. $\mathrm{O}$ "influxo recíproco entre cultura subalterna e cultura hegemônica" (GINZBURG, 1987, p. 13) deu a singularidade da concepção [sugestão: conferiu singularidade à concepção] étnica-cultural do povo Chiquitano, que o diferencia até mesmo das outras etnias indígenas que se formaram no mesmo período e de contextos similares na América invadida e colonizada.

Eles permaneceram 'invisíveis' até metade do século XIX, quando Bolívia e Brasil proclamaram suas repúblicas. Algumas batalhas armadas no período de guerra pela independência boliviana intensificaram o deslocamento dos indígenas chiquitanos para o hoje denominado Mato Grosso, na região de Casalvasco, cuja configuração perdura no desenho geográfico do território chiquitano no Estado brasileiro. O estágio mais definido das fronteiras entre as duas nações colaborou para um momento de maior tranquilidade para que essas mulheres e homens Chiquitanos pudessem produzir suas vidas longe das guerras; todavia, tais linhas fronteiriças não representavam uma barreira social para as relações estabelecidas entre os Chiquitanos desses países, de cuja divisão a maioria nem sequer sabia. Essa organização social no espaço/tempo chiquitano ressignificou as relações com o território tradicional: a sobrevivência a partir das relações entre os seres humanos e a natureza assume outros aspectos pelo distanciamento das missões, o isolamento no interior das fazendas e outros novos arranjos geográfico-ambiental, ou seja, da terra e os recursos existentes nela. $\mathrm{O}$ que manteve a unidade chiquitana foram as tradições conservadas, principalmente as ligadas à religiosidade, à cosmologia dos sujeitos e seus respectivos imaginários de uma sociedade que acredita e participa, aos laços históricos e, mais intimamente, aos laços familiares, base de toda sistematização das aldeias chiquitanas. $\mathrm{O}$ aspecto cultural, então, determina a identidade de si, entre si e para o outro como um mesmo povo, que se identifica como Chiquitano.

A produção da subsistência, resultante da transculturação interétnica entre o ameríndio e o jesuíta, favorece o conjunto social, baseado na prática de coleta, caça e pesca, no cultivo de roças e no uso coletivo da terra, a fim de garantir o bemestar de toda comunidade. A divisão do trabalho segue a dimensão cosmológica que os sujeitos possuem da natureza, estendendo-se aos outros seres vivos. Ela está entrelaçada ao Divino. Deus, criador de toda natureza e esta, por sua vez, perfeita e portadora de toda divindade, são concebidos com unicidade. Assim, os seres que da terra recebem a graça da vida, e para a terra devem voltar. Em um dos mitos que se referem à origem dos Chiquitanos, Deus criou o homem e a mulher a partir da releitura da história narrada no livro Gênese, da Bíblia Sagrada seguida pelos católicos. Na história contada pelos indígenas anciões da etnia, a criação ganha significados que os ligam intimamente ao território tradicional, como, por exemplo, os Chiquitanos terem sido enviados por Deus através do Portal do Encantado, região sagrada localizada na Serra de Santa Bárbara, hoje Parque Ecológico do estado do Mato Grosso. Segundo a crença, todas as graças são enviadas também por esse portal, como os animais, a fertilidade, as chuvas, a saúde etc. Da mesma forma, dele vem a água. Assim, a agência própria dos Chiquitanos e dos outros seres que habitam os elementos da natureza chamados hitchis, como uma forma de indigenismo que perpassa e articula suas identidades no cuidado com suas igrejas, com suas fontes de água e córregos, com seus rituais e no toque de suas músicas (PACINI, 2012).

Esse processo ocorre em um tempo/espaço concreto de vida, no qual as pessoas produzem, além da subsistência, suas culturas marcadas pela tradicionalidade que "carregam o sentimento de 'ser', 'estar' e 'permanecer' " (SOUZA; BRANDÃO, 2012, p.117), compondo uma comunidade na qual os seus sujeitos sociais, ao viverem entre si e com a natureza, constituem ao longo da própria história, significados com tudo com que mantêm contato, como o território, a água, 
os alimentos, outros seres vivos, o mundo, as mulheres e os homens que nele existem.

Pontualmente, podemos observar que a vida acontece predominantemente em função do nós. Nenhum evento ocorre isolado, e as decisões são tomadas pela comunidade. Mesmo os líderes não agem pelo interesse próprio ou sob influência de outrem. A hierarquia não tem caráter absoluto; ela significa respeito que têm àqueles que portam a sabedoria da vida. Neste caso, os anciões têm uma importância maior do que o cacique em uma aldeia chiquitana. Nessa relação de reciprocidade é necessária a sabedoria para liderar, assim como o de 'obedecer', respeitando os contextos e necessidades de cada momento. Logo, entendemos que as relações com a natureza e com pessoas, por mais diversas que apareçam, são caracterizadas pela inter-relação, que se opõe ao supérfluo e ao corrosivo.

Não há separação entre as instâncias da organização da vida. Trabalho, Religião, Família, Educação, Natureza e assim por diante, são na sua essência a mesma coisa. Ou seja, a produção material e imaterial da vida na experiência chiquitana resultou no processo de produção associada, em que prevalece a supressão das necessidades da comunidade. Todavia, uma vez que sua existência implica a inter-relação com a natureza, esta, quando se extingue, extingue também o povo Chiquitano. Ameaças concretas que se desenvolveram na segunda metade do século XX, com a expansão das fronteiras agropecuárias do capital, comprometeram a produção ampliada da vida indígena, que se deparou com uma nova/velha forma de colonização e efetivo genocídio.

\section{Conflito em Terras Sagradas: Território, Identidade, Direitos Humanos e a Perversidade do Agronegócio}

Em meados dos anos 1930, o governo militar do Brasil, implantado por alianças ainda obscuras que objetivavam a consolidação econômico-política do capitalismo nacional e internacional, preocupado em ocupar e garantir o território geopolítico da fronteira, promoveu diversas políticas como a 'Marcha para o Oeste', em 1938, que convocava os 'verdadeiros brasileiros' para colonizar as terras selvagens (PACINI, 2012). Tal episódio deu partida ao processo de expansão das fronteiras agrícolas e pecuárias e que, para garantir os interesses político-econômicos dos fazendeiros, trouxe consigo desumanas desocupações indígenas do território tradicional. A inexistência de documento tornou-os alvos de políticos, que os expulsaram de seus territórios sagrados sem maiores problemas, pois, como a concessão de terra particular deveria ter autorização da União, não havia obstáculos administrativos que protegessem os direitos dos povos indígenas, como a Lei da Terra de 1850, que estabelece restrição de "acesso às terras localizadas até cento e cinquenta metros da linha fronteiriça" (PACINI, 2012, p.18).

A desintegração das famílias chiquitanas de seu território tradicional gerou também prejuízos de desenraizamento desse povo e não raro a extinção de comunidades inteiras, como o caso da aldeia São José, no município de Vila Nova da Santíssima Trindade. A dimensão da perda para o povo é irreparável, visto que ficaram fragilizadas a garantia da produção e reprodução da vida, material e imaterial. Nesta última encontramos, por exemplo, a impossibilidade de familiares velarem os seus mortos nos locais sagrados dos cemitérios indígenas, dada ordem de fazendeiros, que proíbem a entrada nas áreas 'privadas'.

No passado não era necessário exprimir medidas exatas de fronteira, vivia-se com base nos próprios costumes chiquitanos. As mudanças na paisagem com as fazendas trouxeram sérias consequências na orientação dos Chiquitanos que se tornaram empregados, visto que não mais trabalham de modo tradicionalmente organizado na região, mas divididos por cada fazendeiro que os isola $e$ os individualiza segundo os padrões do capitalismo ocidental, tornando difícil sua organização ou mobilização enquanto etnia indígena nos dias atuais. (PACINI, 2012, p.42)

As invasões realizadas pelos fazendeiros, na sua maioria envolvidos diretamente na política do Estado, deu-se mesmo sem a posse efetiva da terra, ou seja, sem a possuírem legalmente, mas sim pelo uso do poder absoluto do capital e da coação física e moral. Para executarem a grilagem das terras, o uso da violência predominou nas ações de ocupação e expulsão dos indígenas e outras comunidades tradicionais existentes.

Os Chiquitanos passaram a ser conhecidos por não entrarem em conflito direto com os usurpadores dos seus recursos naturais, matas e território, por possuírem o traço que predomina nesse período, de resistência 'pacífica', dada a grande desvantagem a que os indígenas ficaram expostos com as medidas de ordem civil estabelecidas nos governos brasileiros. A aliciação da mão de obra praticamente escrava de famílias inteiras passou a ser comum em fazendas da região, 
pois, além da fama de 'dóceis', tinham também a de bons na lida com o gado e no trato com a terra. Desde então, eles se tornaram parte da 'massa' pobre da fronteira brasileira, os bugres, forma pejorativa como são chamados pela população não indígena local. Assim, muitos chiquitanos mantiveram relações de trabalho de exploração.

Os locais em que estão, dentro de fazendas, beiras de estradas, na zona neutra da fronteira, na periferia das cidades, não permitem o cultivo da terra e isso os obriga a procurar trabalhos assalariados para garantir o sustento familiar. Existe trabalho nas fazendas somente para os que não se reconhecem como indígenas. Em muitas comunidades os conflitos pela posse da terra fizeram com que Chiquitanos fossem mortos e a maioria fugisse para a Bolivia ou para as cidades, e estas comunidades já não existem mais. Exceção a isso são os casos das comunidades de Vila Nova Barbecho e as do Portal do Encantado. (PACINI, 2012, p. 67)

Pacini (2012) elucida um pouco de como estão os Chiquitanos que vivem no lado brasileiro. Apenas alguns grupos resistiram ao genocídio, uma resistência que toma forma de luta, que se contrapõe à visão colonialista e autoritária dos 'civilizados' sobre a apropriação, pois à terra se acrescentam a fé e o significado da própria existência. A necessidade de sobrevivência facilitou a inserção das mulheres e dos homens indígenas como mão-de-obra explorável. Além disso os Chiquitanos se aproximaram dos colonizadores para não serem considerados selvagens ou bárbaros e, dessa forma, não serem atacados e mortos ${ }^{4}$. As Repúblicas tinham a civilização ocidental como ideologia ${ }^{5}$; logo, vislumbravam a integração do índio ao Estado como trabalhador produtivo. Isso contribuiu para outra problemática que emerge nos conflitos e no direcionamento das lutas mais recentemente: a negação da etnicidade. Como tática política, os fazendeiros-políticos atacaram a etnia, utilizando-se da mídia capitalista através das

[...] políticas de negação da etnicidade, lideradas por políticos de grande influência no estado de Mato Grosso, utilizando estes veículos dependentes dos favores do estado, sem qualquer fundamento científico sobre o Chiquitano, a fim de confundir a população local, e reforça a negação da presença indígena na região. (GRANDO \& QUEIROZ, 2013, p. 455)
Dessa forma, podemos ver quão conflituosa é a questão identitária dos Chiquitanos, pois nem as fronteiras políticas dos Estados, nem a imposição econômica dos grandes proprietários de terras, nem mesmo nas nacionalidades culturalmente distintas apagaram o sentido de ser chiquitano. Segundo Pacini (2012, p. 590), essa política de negar a identidade indígena também resulta do "jogo de mobilidade fronteiriça e dos sentidos de pertença identitária", que "são negociados com criatividade dentro dos circuitos burocráticos de coerção e controle do Brasil".

Há ainda grandes problemas encontrados por eles relacionados à histórica 'barreira social' que vivenciam, pois fazem um imenso esforço para continuar os laços de parentesco nos dois lados da fronteira, através de caminhos que constroem, para participar das comunidades espalhadas na sagrada região com sentimento de coletividade, pois tal linha, que separa os dois países (Brasil e Bolívia), não possui legitimidade no território chiquitano, de cuja existência somente se aperceberam na década de 1990 (SILVA, 2012), com a construção do gasoduto $^{6}$. Contudo, cada vez mais esse território é invadido, seja por fazendeiros que garantem a posse das terras por vias perversas ou pelo Estado do Mato Grosso, que facilita $^{7}$ a expansão do agronegócio. Assim, ao longo da história, os chiquitanos foram espremidos em minúsculas regiões na periferia das cidades e beiras de estradas, sendo obrigados a deixar suas águas sagradas, cada vez mais distantes e vulneráveis.

No Brasil, o território chiquitano é visto como uma ameaça aos fazendeiros $e$ políticos que tentam a todo custo negar a existência da etnia indígena, pois se os Chiquitanos se dizem indígenas, possuem direito ao seu território tradicional, mesmo que já tomado pelos fazendeiros e políticos. (PACINI, 2012 apud IHUONLINE, 2012, $s / p)$

O processo de negação dos chiquitanos enquanto indígenas é de ordem coronelista, imperialista e intimidadora. Ela advém de uma campanha de cunho político que visa agregar diretamente a imagem do Chiquitano à ocupação imigratória, tratando-os, assim, como estrangeiros que vêm usurpar de terras brasileiras - além de outras colocações pejorativas que já estão disseminadas no senso comum sobre os indígenas e imigrantes. A invisibilidade desse povo tem como pano de fundo a extrema exploração de sua mão de obra, das riquezas da terra e dos cercamentos dos territórios tradicionais. 
Como existem outras dez ou doze comunidades de Chiquitanos e como a FUNAI já havia designado em 2002 ou 2003 novos grupos de trabalho para identificação de outras áreas, eclodiu um conflito - que estudei em Silva (2008) capitaneado por políticos locais buscando afirmar que tratava-se de bolivianos e não de índios, e que a indianidade deles era invenção da FUNAI e de uma antropóloga (no caso, a autora deste artigo). (SILVA, 2012, p. 124)

As represálias que buscam minar a identidade chiquitana pelos pares produzem simultaneamente o sentimento do fortalecimento étnico-cultural e a necessidade de novas articulações que desenvolvem as relações sócio-políticas interna e externamente. E fundamental, para compreendermos quais as implicações concretas que os conflitos exercem na cultura e na consciência dos Chiquitanos, analisar algumas questões no cotidiano das comunidades a que pertencem.

A realidade de algumas das aldeias foi por nós conhecida durante a pesquisa. Vila Nova Barbecho, Acorizal, Fazendinha e Nossa Senhora Aparecida foram algumas das comunidades em que foram realizadas observações previstas na metodologia do trabalho. Acorizal e Fazendinha estão no território sagrado denominado Portal do Encantado, cujo processo de demarcação pela União Federativa está mais adiantado, estando 'parado' na última instância, pois já foi identificada e delimitada. $\mathrm{O}$ que colaborou com o processo foi a proximidade com o Parque Ecológico Estadual da Serra de Santa Bárbara e o destacamento militar Fortuna, reduzindo, assim, os interesses privados na atualidade. Todavia, o processo não prossegue, por interesses políticos, liderados pela bancada parlamentar ruralista. Já as aldeias Vila Nova Barbecho e Nossa Senhora Aparecida encontram-se à beira de grande conflito, sofrendo com as ameaças constantes e de efetiva violência por parte dos fazendeiros que as cercam. Na primeira, após decisão judicial de discutível embasamento, os chiquitanos ficaram confinados a 25 hectares de terra. Nessa comunidade há mais quinze famílias, que somam por volta de cem indígenas. São mulheres e homens, crianças, jovens e idosos, que sofrem com a falta de recursos que lhes garantam a sobrevivência. O caso mais grave ocorreu em 2006, quando o fazendeiro jogou serragem no córrego Nopetarch, contaminando a única fonte de água da comunidade. Ato intencional perversamente executado como estratégia de expulsão dos indígenas de seu território sagrado, infelizmente atitude comum empreendida pelos proprietários de terras do Brasil. Além da contaminação da água, que resultou na mortandade dos peixes, fonte de alimento dos indígenas e outros animais do ecossistema, os fazendeiros também investiram com ameaças de morte destinadas ao cacique Fernandes Muquissai e outros moradores da aldeia, como Soilo Urupe Choe e sua irmã Saturnina. Esta teve sua casa queimada em ato de represália. Todos os eventos são de conhecimento do Poder Judiciário nas diversas instâncias, inclusive do Ministério Público Federal $^{8}$. O processo de demarcação dessa aldeia, que corre desde 1999, hoje voltou a ser movimentado pela última ameaça de morte destinada aos trabalhadores que foram executar uma obra da construção de um poço artesiano de água, expedida por ordem judicial em medida de urgência, todavia inconclusa pelo ato de terror ocorrido.

Porém a situação mais precária é da aldeia Nossa Senhora Aparecida. Nesta, mesmo a assistência de saúde foi proibida por ações de terrorismo dos fazendeiros da região, que aliciam até mesmo alguns Chiquitanos. Trata-se, neste caso, de um grande conflito interno, semeado novamente como estratégia de anulação da presença indígena nesse território, pois ela acarreta a impossibilidade de exploração das terras e dos recursos nela contidos. A condição dessa aldeia configura algumas implicações no tocante à identidade indígena. Primeiro, pelo fato de os que se reconhecem como tal serem ofensivamente hostilizados, um preconceito, como já relatamos, incitado pelas políticas de negação da etnicidade. Além disso, como não há nenhuma garantia de recursos para produção material da vida, ou seja, da sobrevivência, a maior parte dos chiquitanos veemse obrigados a trabalhar nas fazendas da região e, uma vez que reconheçam sua etnia, não terão mais seus trabalhos. Para que possam morar em sua terra, criar seus filhos e sobreviver, essas mulheres e homens negam sua identidade por vergonha, por medo ou apenas por falta da esperança, pois o Estado já não possui credibilidade diante da realidade percebida, pela consciência que os chiquitanos possuem da desigual e covarde implementação das leis e da desumanidade que perpassa os interesses dos grandes fazendeiros sentida na pele. Nesse episódio, a maioria dos chiquitanos negam a si, negam suas origens, negam sua história e sua cultura indígena. Em contrapartida, aqueles que assumem a identidade indígena, além de assumir concomitantemente todos os preconceitos nela embutidos, sofrem com as represálias, ameaças e o medo que nos últimos doze anos foi intensificado, pois e, absolutamente, nada foi feito. O território sagrado Baía Grande foi 
transformado pelo agronegócio, em um Estado cuja lei é para benefício do capital e do poder.

\section{Resistência: a consciência despertada para uma pedagogia de luta}

As situações de conflito são intensificadas com a precarização da condição humana, pois "o modo de produção da vida material condiciona o processo da vida social, política e espiritual em geral" (MARX, 2008, p. 47), ou seja, em última instância, o que prevalece é garantir a existência. Todavia, mesmo prevalecendo sistemas dominantes de organização social e de estruturação do trabalho, as mulheres e os homens chiquitanos são sujeitos de sua própria história. Nesse sentido, o povo chiquitano, que sofre com a degradação de sua humanidade e da natureza, a qual é a extensão de sua própria essência, no processo da contradição que é exposto, cria e recria suas tradições, seus costumes, seus valores.

As diferenças sociais não são simplesmente dadas a experiência através de uma tradição cultural já autenticada; elas são os signos da emergência da comunidade concebida como projeto - ao mesmo tempo uma visão e uma construção - que leva alguém para "além" de si para poder retornar, com um espirito de revisão e reconstrução, as condições políticas do presente. (BHABHA, 1998, p. 21-22)

Observamos que eles traduzem a manifestação da consciência de sua condição, seja na forma de resistência ou de 'invisibilidade'. Entendemos que estas não denotam a aceitação da outra cultura, mas sim resultam da opressão que sofrem quando a vida de seus familiares e a sua própria estão ameaçadas. Já aquela configura uma nova modalidade de instituir a cultura.

Esta resistência não se apresenta, necessariamente, de forma violenta, através de motins e outros confrontos. Pequenos furtos, utilizações jocosas de signos do poder, cartas anônimas, canções, inversões, irreverências, representações teatrais, que em sua maioria encontram expressão nas festas, são exemplos das formas simbólicas nas quais pode se apresentar a resistência. (SOIHET, 1992, p. 42)

Tal representação da resistência fora observada logo nas primeiras investigações, apontada pelas experiências de constituição da totalidade do povo chiquitano. Tiriba e Fischer (2012, p. 615) destacam que, "na perspectiva do materialismo histórico, a produção diz respeito à totalidade dos processos de criação e recriação da realidade humano-social mediados pelo trabalho, pelos quais o ser humano confere humanidade às coisas da natureza e humaniza-se com as criações e reproduções que produz sobre o mundo". Logo, a luta pelo território e as relações em torno da questão da identidade transformam a percepção dos conflitos a cada urgência. Pacini (2012, p. 41) observa que, quando "submetidos à perda do território tradicional e o trabalho degradante, as comunidades chiquitanas se organizam para reivindicar, ao seu modo e progressivamente, os espaços territoriais perdidos". Os conflitos têm gerado mudanças também no sentido de ser Chiquitano.

Embora tenham, desde sua gênese, o caráter da resistência dos códigos sociais, a atual experiência de luta os leva a sair do contato com o outro identificado (neste contexto, os fazendeiros), para conhecer a profunda sistematização capitalista e suas relações com o agronegócio. Esse é o processo histórico em que mulheres e homens chiquitanos produzem suas vidas e, simultaneamente, a si mesmos. Para Thompson (1987, p. 10), "a consciência de classe é a forma como essas experiências são tratadas em termos culturais: encarnadas em tradições, sistemas de valores, ideias e formas institucionais". A expressão da fé é um exemplo das correlações entre a experiência, a consciência e a cultura. Durante alguns rituais religiosos, os Chiquitanos buscam refletir coletivamente as lutas em que estão envolvidos. $\mathrm{O}$ território ganhou referência à terra prometida; a prática religiosa é, ao mesmo tempo, prática política. Isso significa que, assim como uma formação religiosa que seria imprescindível na manutenção da vida, sendo a fé uma espécie de alimento ao espírito, a formação política não seria diferente. Depois de algumas gerações, privadas da paz para poder permanecer em suas casas sem o medo da violência, os chiquitanos compreenderam que apenas com a apreensão das formas de luta possíveis encaminharia a sonhada conquista. Quando sofreram de sede, de fome, de medo, proibidos de falar com suas mães e pais na língua materna, de sair de suas casas ou dos frios e escuros esconderijos nas matas; quando perderam suas famílias, seus mortos, sua história, os chiquitanos aprenderam com a tristeza e a dor o valor da paciência, da persistência e da resistência. Uma consciência que vem ganhando maiores dimensões.

A educação, então, tornou-se um campo que privilegia essa formação política. Uma das 
providências presentes nas pautas de luta, dos encontros entre as lideranças indígenas e em reuniões com as instituições competentes, tem sido a criação de escolas indígenas chiquitanas, pois confiam em que ela, enquanto instituição sistematizadora do saber, somente daria conta de seu devir, ou seja, de transmitir os saberes que a eles interessam, através de um sistema educacional próprio, legitimado pela sua práxis, conciliada à vida chiquitana.

O sucesso das escolas diferenciadas tem sido promissor. Elas têm garantido qualidade no processo de ensino-aprendizagem pelo empenho dos professores envolvidos - membros da própria comunidade - e pela motivação dos alunos que desfrutam de uma educação que leva em consideração a realidade que vivem. Além disso, fortalece a identidade étnico-cultural chiquitana, colaborando com a luta pela demarcação do território tradicional.

Em toda extensão do Estado do Mato Grosso, segundo o Censo 2013 da Secretaria Estadual de Educação - SEDUC (MATO GROSSO, 2013), estão registradas 208 escolas diferenciadas para as diversas comunidades indígenas, somando um total de 19.206 indígenas matriculados entre as séries multiciclicas e a Educação para Jovens e Adultos (EJA). Isso corresponde a 7,5\% do total de escolas existentes no Estado, um número ainda reduzido, visto que há mais de 47 etnias, e a maioria ainda não possui escola pela burocratização do acesso ao direito à educação institucionalizada. Dentre as aldeias chiquitanas, apenas duas possuem escolas indígenas: a Escola Estadual Indígena Chiquitanos, que atende as crianças do território do Portal do Encantado, e a Escola Estadual Indígena Chiquitana José Turíbio, que atende as crianças da aldeia Vila Nova Barbecho. No caso das escolas indígenas chiquitanas, o sistema escolar segue os mesmos padrões previstos nas legislações que regem a educação nacional das escolas não indígenas. Todavia, o que se especifica é a apreensão do sistema pelos indígenas, que se tornam protagonistas do fazer pedagógico quanto mais se apropriam das ferramentas e espaços educacionais como parte socializadora dos saberes acumulados pela experiência de luta chiquitana. Nessas localidades, a educação chiquitana possui peculiaridades relativas às experiências autóctones, jesuítas, coronelistas e capitalistas, caracterizandose como uma educação antissistêmica, tal como sua cultura.

A educação não se restringe à escola e esta não é aceita senão quando condizente à sua realidade. Logo, as escolas chiquitanas não apenas cumprem seu devir institucional, mas também se estendem ao cotidiano. A escola não tem paredes com a vida, e, segundo Paula (2010, p. 45), "os professores e os anciões têm um peso muito grande nas discussões e na deliberação de qualquer demanda", pois eles são os primeiros a desempenhar o papel de intelectuais orgânicos frente à luta pelo direito à terra e à vida na comunidade chiquitana. Assim, os professores são fundamentais para a realização da educação institucional que se diferencia pela essência de seus propósitos, pois eles especificamente deverão ser conhecedores da própria cultura como requisito para o desenvolvimento do trabalho pedagógico.

Outras características que singularizam as escolas chiquitanas estão relacionadas ao seu projeto político-pedagógico, a começar pelos seus espaços e estruturas ocupados para o ensinoaprendizagem, os conteúdos temáticos abordados e os materiais utilizados para tanto. Mesmo no que diz respeito à rotina escolar podemos observar peculiaridades ao sistema educacional chiquitano. As escolas são construídas nas aldeias conforme são tradicionalmente adaptadas às moradias indígenas chiquitanas, contendo inclusive a cozinha no mesmo modelo. Dentre os conteúdos, além daqueles ensinados nas escolas não-indígenas como exigência dos critérios de avaliação, os temas privilegiados são os ligados à natureza, às tradições, à língua materna e às artes, todos representantes da legitimação identitária do povo Chiquitano. Acreditamos que a identidade possui um inestimável valor para os chiquitanos, pois é aquilo que ninguém lhes tira até sua morte, aquilo que levam consigo por onde caminhem, dancem, durmam, comam ou sonhem. Com isso, a educação é centrada nas questões que afirmam e (re)significam os costumes, valores e tradições chiquitanas presentes em suas músicas, danças, manifestação da fé, pinturas, culinária, rituais e linguajar, um processo que conta com a participação de todos os membros da comunidade, como afirma Paula (2010, p. 106-107):

Além do envolvimento dos anciões nas aulas de língua portuguesa e língua materna, os professores têm envolvido outros membros da comunidade conhecedores da cultura do povo Chiquitano, como é o caso do artesanato, construções de casas e de utensílios domésticos. Esses assuntos são temas das aulas de matemática, história e arte.

Exemplos não faltam, porém destacamos o ensino na música barroca missional na escola indígena chiquitana José Turíbio, em que as 
crianças e jovens chiquitanos aprendem a sua arte ancestral como parte das tradições herdadas da circularidade cultural entre a origem autóctone e o período das reduções jesuítas. Na escola, esses pequeninos chiquitanos formaram a orquestra Espírito Santo dos Chiquitos, regida por maestros chiquitanos que já fizeram um percurso dedicado à música barroca chiquitana na Bolívia, pois este país não esconde ou desvaloriza seu povo. Na aldeia Vila Nova Barbecho, o maestro Lorgio, chiquitano de Santa Ana (Bolívia), ensina as crianças e jovens a tocarem instrumentos diversos e composições que são executadas nas igrejas chiquitanas e nos grandes festivais promovidos internacionalmente, sendo algumas dessas folclóricas. O interessante é que a unidade chiquitana facilita a linguagem entre o português, o espanhol, o besiro (língua materna chiquitana) e a música, provocando uma sintonia inexplicável, inspirada nas águas, no vento, nos pássaros e no amor. Além da música, também vislumbramos uma educação para formação integral do ser humano, que contempla a corporeidade indígena dos chiquitanos através, por exemplo, do curussé, uma dança circular em que os indígenas arrastam seus pés, dançam em roda, sozinhos ou em pares - uma dança que vem de suas almas e que inevitávelmente nos contagia. O curussé, presente em todas as festas tradicionais, é a mais contagiante demonstração de alegria desse povo. Embora haja outras danças tradicionais que ritualizam algumas importantes festividades religiosas, o curussé se destaca pela sua improvisação coletiva dos movimentos encarnados pela comunidade, como um balanço ancestral que os liga a natureza e aos seus, revigorando o sentido da vida e da identidade chiquitana. O curussé existe a partir do carnavalito instituído pelos jesuítas e, junto à música feita da caixa, bombo, pífano e flauta, harmonizam e alegram o momento de preparação para a Páscoa, pois a festa é parte da relação com a fé e o bemviver da comunidade, carregando consigo o sentido de ser dos Chiquitanos.

Os professores são todos chiquitanos e construíram suas trajetórias enquanto educadores de formas distintas, porém desenhadas no chão da resistência transmitida por seus ancestrais. A língua materna, fundamental à manutenção da cultura étnica desse povo, tem sido retomada pelos professores após um triste período em que foram proibidos de utilizá-la pelos fazendeiros da região, "e são eles, anciões, que apesar de analfabetos, os responsáveis por ensinar a pronúncia correta da língua materna, aos alunos e professores" (PAULA, 2010, p.105). A autora relata a importância também do lançamento pelo governo brasileiro do Referencial Curricular Nacional para as Escolas
Indígenas - RCNEI, em 2002, “onze anos após a criação da categoria escola indígena",

Com o objetivo de oferecer subsídios $e$ orientações para a elaboração de programas de educação escolar indígena que atendam aos anseios e aos interesses das comunidades indígenas, considerando princípios da pluralidade cultural e da equidade social. [...] $O$ RCNEI foi concebido com função formativa e não normativa.

Esse parâmetro contemplou as escolas indígenas com maior autonomia, já prevista pela Constituição Federal de 1988, e incentivou a abertura cada vez maior de escolas indígenas assim como a formação dos professores dessas escolas. Nesse sentido, os professores Chiquitanos têm se movido entre as duas comunidades que possuem as escolas indígenas e participado das formações oferecidas pela Universidade Estadual de Mato Grosso - UNEMAT, pelo Centro de Formação e Atualização de Professores - CEFAPRO, e pela Assessoria Pedagógica da SEDUC. Para que isso seja possível, as formações são realizadas nos períodos das férias escolares e em conjunto nas próprias aldeias, sendo fundamental a participação da comunidade na construção dos currículos e avaliação dos trabalhos desenvolvidos.

Uma terceira escola está em processo de criação, cuja idealização fora manifestada pelo cacique Aurélio, da aldeia Nossa Senhora Aparecida, em uma das reuniões junto à Fundação Nacional do Índio - FUNAI, onde se expuseram os problemas e expectativas do povo chiquitano que vive naquela aldeia. $\mathrm{O}$ cacique Aurélio manifestava naquele tempo/espaço político uma necessidade da comunidade para sua sobrevivência em meio à avalanche que caía sobre os chiquitanos encurralados pelas ameaças e pelo isolamento físico e administrativo.

Além da educação através das escolas diferenciadas nas aldeias, os chiquitanos experimentam outras vivências, como a inserção recente nas universidades, facilitada pelos programas do governo federal que sustentam a reserva de cotas para indígenas e processo seletivo entre indígenas, como também incentivos para os já universitários, como o Programa de Inclusão Indígena - PROIND, que na Universidade Federal de Mato Grosso - UFMT tem como representante o indígena chiquitano Soilo Urupe Chue. Mas essa educação superior, na opinião dos indígenas, ainda está longe daquela que eles fazem em suas aldeias, opinião que retrata a ludicidade com que os 
chiquitanos enfrentam, no seu cotidiano, os limites da educação formal e vão além, propondo novas perspectivas pedagógicas, políticas educacionais e sistemas de ensino-aprendizagem, que começam a mostrar resultados nas possibilidades criadas nas aldeias e que agora são experimentadas pelas crianças Chiquitanas.

Essas dinâmicas reforçam a totalidade da consciência dessa etnia. Os saberes produzidos por essas pessoas mostram uma cultura específica. Quando buscamos definir sua cultura, falamos "sobre o significado de um modo de vida" (CEVASCO, 2003, p.23). Uma vez que suas vidas estão arraigadas na necessidade de resistir, constituem uma cultura de resistência.

A produção das ideias e as representações da consciência aparecem a princípio diretamente entrelaçada à atividade material $e$ ao intercâmbio material dos homens como a linguagem da vida real. As representações, o modo de pensar, a comunicação espiritual entre os homens se apresenta aqui, como a emanação direta de sua relação material, tal como se manifesta na linguagem da política, das leis, da moral, da religião, da metafísica etc. de um povo. (MARX e ENGELS, 2007, p. 93)

\section{Considerações Finais}

O povo Chiquitano está presente na vasta região que ultrapassa a fronteira geopolítica entre a Bolívia e o Brasil. Estima-se que neste existam mais de três mil chiquitanos espalhados em diversas conjunturas, como em aldeias, beiras de estradas, estabelecimentos junto aos destacamentos militares e "nas periferias das cidades de Porto Espiridião, Cáceres e Vila Bela da Santíssima Trindade" (SILVA, 2012, p. 119). A costura étnica entre os dois países através do povo chiquitano demonstra que, para além da incoerente fronteira estabelecida, há uma preciosa articulação da vida e dos arranjos socioculturais que essas comunidades criam e recriam para manter suas identidades e os laços familiares. Essas estratégias aparecem nas diversas instâncias da produção ampliada da vida.

Nos trabalhos realizados pelos pesquisadores Costa (2006), Silva (2012) e Pacini (2012), além de outros, os chiquitanos aparecem como possuidores de uma essência cosmológica atrelada a uma cultura singular, cuja formação histórica preconiza uma lógica social de representação simbólica ligada à sua religiosidade cristã-indígena, como também ao território tradicional, pois "é nesse espaço que os índios
Chiquitanos se articulam, buscam trabalho, circulam, lavram a terra, celebram o sagrado e que, de certa forma, permitem organizar uma troca pela sobrevivência, onde os recursos encontram-se cada vez mais escassos" (COSTA, 2006, p.20).

A ampla práxis empírica possibilita uma consciência coletiva, pois, "apesar de estarem inseridas no sistema capitalista, essas estratégias populares apontam princípios que denotam uma velha/nova racionalidade econômica" (NEVES, 2013 p. 67). As relações com a natureza, por mais diversas que pareçam, são caracterizadas pela interrelação. A subsistência é cultivada pelo entendimento oposto ao efêmero e ao descartável, que se pressupõe supérfluo e corrosivo. Toda essa dinâmica sociocultural permite aos Chiquitanos múltiplas habilidades, destrezas e competências, tornando-os assim sujeitos amplamente desenvolvidos nas possibilidades humanas, a qual

[...] só pode consistir em que o homem socializado - os produtores associados regule racionalmente o seu intercâmbio material com a natureza, ponha-o sob seu controle em vez de deixar se controlar por ele como um poder cego e o realize com o menor gasto possível de energia e nas condições mais adequadas e mais dignas da sua natureza humana. Mas, ainda sim, este continuará a ser o reino das necessidades. Mais além dele começa o desenvolvimento das forças humanas como um fim em si, o verdadeiro reino da liberdade - que, no entanto, só pode florescer tendo por base o reino das necessidades. (MARX, 1974, p. 942)

As culturas nascidas da produção associada são tradutoras de uma complexidade de relações que ratificam a impossibilidade de interpretação social do trabalho apenas em termos econômicos. Os trabalhos coletivos visam ao bem comum; dessa forma, opõem-se à cultura hegemônica. As experiências vivenciadas pelos Chiquitanos formaram uma consciência de alteridade em face das opressões e ao reconhecimento do outro, cujos interesses são antagônicos, ao mesmo tempo em que se identificam com o "nós", mulheres e homens cujos interesses são comuns. Assim, no modo de produção associada, mulheres e homens chiquitanos forjam (e se forjam) saberes e valores humanos fundamentais, de maneira acentuada.

A participação da comunidade nos processos educacionais é determinante na constituição das identidades chiquitanas e a relação destas com o processo de luta e produção da vida 
indígena no Brasil. Os professores indígenas, assim, são protagonistas de uma outra educação, que escreve sua história nas aldeias indígenas com caráter emancipatório, autônomo e peculiar. Como afirma Paula (2010, p. 102),

Ser professor em comunidade indígena vai além da vontade e condições de exercer a prática docente. Muitos adentram no contexto da educação escolar por meio de uma necessidade coletiva da comunidade. Para ser docente indígena é necessário que, além das habilidades específicas do ensino, haja a aceitabilidade do professor por parte da comunidade onde a escola se insere. Assim, a educação escolar indígena apresenta uma característica que vai além da organização institucional governamental, ela esparrama-se como raizes e alcança outros espaços sociais e organizações da comunidade.

A solidariedade não é apenas o meio, mas também o fim que buscam alcançar enquanto sociedade e ser social. "Se o que acontece dentro das normas muda, estas continuam importantes, e elas próprias informam o simbolismo derivado do sistema cognitivo oculto pertencente a uma comunidade" (THOMPSON, 2001, p.249). Ou seja, o que muda para o Chiquitano, no instante em que o outro se opõe como absoluto, com disposição de domínio e exploração, são as experiências resultantes dos conflitos sociais. Estas, por sua vez, refletem-se nas escolhas para cada necessidade gerada e, assim, recriam-se pela educação, seja ela através da educação diferenciada ou no chão da vida, uma cultura de resistência.

\section{Notas}

1 Definição de Produção Ampliada da Vida.

2 Definição de Produção Associada.

3 O termo Chiquito foi atribuído pelos colonizadores ainda no século XVI, cujo generalizava habitantes da atual região oriental da Bolívia e parte ocidental do Brasil (ver COSTA, 2006, p. 15). Logo D'Orbigny estabelece que os que fossem da província de Chiquitos deveriam ser chamados de Chiquitanos. Optamos por utilizar Chiquitano - no singular, pela consecutiva adoção entre os antropólogos brasileiros, como afirmam Santana e Dunck-Cintra (2009, p. 92): "A grafia dos nomes tribais no singular seguirá a convenção sugerida durante a $1^{\text {a }}$. Reunião Brasileira de Antropologia, realizada no Rio de Janeiro, em 1953, cujo texto foi publicado na Revista de Antropologia Local São Paulo, v. 2, n. 2, dez. 1954".
4 Ao mínimo de resistência que apresentassem muitos Chiquitanos eram humilhados e violentados. Com isso, tornaram se um povo que procurou acomodar-se à condição de 'bugres', uma espécie de transição entre o civilizado e o índio, porém sem direitos plenos, como forasteiros, presos à condição do medo.

$5 \mathrm{Na}$ obra A ideologia alemã, Marx e Engels trabalham com a categoria Ideologia, na qual afirmam serem as ideias dominantes "a expressão ideal das relações materiais dominantes, as próprias relações materiais dominantes concebidas como ideias" (MARX \& ENGELS, 2007, p. 47).

6 "Como condicionante à execução da obra, foi realizado um estudo de licenciamento ambiental para a construção do gasoduto Bolívia-Mato Grosso, o qual evidenciou a existência de bugres na região de abrangência do empreendimento. Bugre é a designação pejorativa dada aos índios da região da fronteira Mato Grosso-Bolívia pela população local" (COSTA, 2006, p.15)

7 Ver o Projeto de Lei $n^{\circ}$. 349/2013, da senadora de Kátia Abreu (PSD-TO), além da PEC 215 que transfere a demarcação de terras indígenas ao Congresso em tramitação na Câmara dos Deputados e as outras: PEC 38, PEC 237, PLP 2272, Projeto de Lei 1610".

8 Ver Processo $\mathrm{n}^{\mathrm{o}}$ 2006.36.01.001484-2; Classe 7100: ação civil pública; Ministério Público Federal/Justiça Federal/ Subseção de Cáceres MT.

\section{Referências}

BHABHA, Homi. O local da cultura. Tradução Miriam Ávila, Eliana Lourenço de Lima Reis e Gláucia Renate Gonçalves. Belo Horizonte: Editora UFMG, 1998.

CEVASO, Maria Elisa. Dez Licões de Estudos Culturais. 1. ed. São Paulo: Boitempo, 2003.

COSTA, José Eduardo Fernandes Moreira da. A Coroa do Mundo: religião, território e territorialidade Chiquitano. Cuiabá: EdUFMT, 2006.

GINZBURG, Carlo. O queijo e os vermes. São Paulo: Companhia das Letras, 1987.

GRANDO, Beleni Salete; QUEIROZ, Letícia Antonia. A educação do corpo em Vila-Nova Barbecho: o Curussé Chiquitano na criança. Revista Educação Pública. Cuiabá, v. 22, n. 49/2, p. 453470, maio/ago. 2013. 
IHUONLINE. Chiquitanos e a busca pelo território. Entrevista especial com Aloir Pacini. Revista IHU (on line), março 2012. Disponível em: < http://www.ihu.unisinos.br/entrevistas/chiquitanose-a-busca-pelo-territorio-entrevista-especial-comaloir-pacini/507557-chiquitanos-e-a-busca-peloterritorio-entrevista-especial-com-aloir-pacini>. Acessado em 20/10/2013.

MARX, Karl. Contribuição à crítica da Economia Política. 2. ed. São Paulo: Expressão Popular, 2008.

O Capital. Crítica da economia política. Livro III. Rio de Janeiro: Civilização Brasileira, 1974.

MARX, Karl; ENGELS, Frederic. A Ideologia Alemã. São Paulo: Boitempo, 2007.

MATO GROSSO. Secretaria de Educação do Estado. Superintendência de Gestão Escolar. Gerência de Informação e Estatística. Censo Escolar 2013. Disponível em: <http://www.seduc.mt.gov.br/Paginas/censoescolar-indicadores.aspx $>$ Acessado em 11 de novembro de 2014.

NEVES, Camila Emanuella Pereira. A produção associada em Capão Verde: entre bananas, saberes e utopías. Cuiabá: EdUFMT, 2013.

PACINI, Aloir. Identidade étnica e território Chiquitano na fronteira (Brasil-Bolívia). Tese (Doutorado em Antropologia Social) - Instituto de Filosofia e Ciências Sociais. Universidade Federal do Rio Grande do Sul. UFRGS, Porto Alegre, 2012.

PAULA, Hébia Thiago de. Aspectos culturais e educação ambiental: a vida cotidiana do povo indígena chiquitano. Dissertação (Mestrado em Ciências Ambientais) - Programa de Pós-Graduação em Ciências Ambientais. Universidade do Estado de Mato Grosso. UNEMAT, Cáceres, 2010.

SANTANA, Áurea Cavalcante; DUNCK-CINTRA, Ema Marta. Estudos da língua Chiquitano do Brasil: trajetória e perspectivas. Revista Polifonia. Cuiabá, nº17, p. 91-109, 2009.

SILVA, Joana Aparecida Fernandes. Pertencimento e Identidade, Territorialidade e Fronteira entre os Chiquitanos no Brasil e na Bolívia. Revista Espaço Ameríndio. Porto Alegre, v. 6, n. 1, p. 119-137, jan./jun. 2012.

SOIHET, Rachel. O drama da conquista na festa: reflexões sobre a resistência indígena e a circularidade cultural. Estudos Históricos. Rio de Janeiro, v.5, p. 44-59, 1992.

SOUZA, Angela Fagna Gomes de; BRANDÃO, Carlos Rodrigues. Ser e viver enquanto comunidades tradicionais. Mercator (Fortaleza. Online), v. 11, p. 109-120, 2012.

TIRIBA, Lia. FISCHER, Maria Clara Bueno. Produção Associada e autogestão. In: Dicionário da Educação do Campo. Organizadores: Roseli Salete Caldart, Isabel Brasil Pereira, Paulo Alentejano e Gaudêncio Frigotto. Rio de Janeiro, São Paulo: Escola Politécnica de Saúde Joaquim Venâncio, Expressão Popular, 2012.

THOMPSON, Edward Palmer. A Formação da Classe Operária Inglesa: A Árvore da Liberdade. Rio de Janeiro: Paz e Terra, 1987.

A peculiaridade dos ingleses e outros artigos/ E.P. Thompson. Organizadores: Antonio Luigi Negro e Sergio Silva. Campinas: Unicamp, 2001.

\section{Sobre os autores:}

Marilia de Almeida Silva: Mestre em Educação pela Universidade Federal do Mato Grosso. Atualmente realiza pesquisas no sudoeste mato-grossense, na fronteira do Brasil com a Bolívia, com os povos indígenas da etnia Chiquitano.

Edson Caetano: Graduado em Ciências Sociais pela PUC-Campinas, mestre e doutor em Educação pela Unicamp. Atua como docente do Programa de Pós-Graduação em Educação, da Universidade Federal de Mato Grosso.

Artigo recebido em maio de 2014.

Artigo aprovado em maio de 2015. 